\title{
Development of Mathematical Model for Traffic Flow within Speed Limitation
}

\author{
Oleg Danilov ${ }^{1, *}$, Victor Kolesov ${ }^{1}$, and Denis Sorokin ${ }^{1}$ \\ ${ }^{1}$ Industrial University of Tyumen, 625001 Volodarskogo str. 38, Tyumen, Russia
}

\begin{abstract}
The paper discusses a symbiotic model of the traffic flow, based on the classical model of the longitudinal dynamic gauge of the automobile and an alternative model developed by the authors. The presented mathematical model makes it possible to quantify the dynamic characteristics of the traffic flow for various levels of speed limitation and for a wide range of road conditions. The problem of structural and parametric identification of the mathematical model is challenging. A solution to this problem is based on the traffic flow theory, regression analysis and dynamic programming.
\end{abstract}

\section{Introduction}

Traffic management, road-traffic safety and environmental risks are priorities for improving the standards of living. It is possible to meet the challenges provided the traffic flow management principles (TF) are realized on the road network (RNW). In turn, traffic flow management is intimately associated with the innovative approaches in the field of mathematical modeling. Thus, the TF dynamics analysis, identification of the structure and parameters of the $\mathrm{TF}$ models are the basis for sustainable development of the motor industry.

"Car-Following" or "Follow-the-Leader" models are widely used for road-traffic safety; they are based on the longitudinal dynamic gauge (DG) of the automobile. In 1963 Tanaka proposed some new models based on DG [1]. Updating of the proposed models, development of new alternative solutions will make it possible to complete the tasks related to the study of the TF dynamics [1-19].

\section{Technique}

The classical model of the longitudinal dynamic gauge is as follows:

$$
L(V)=m_{2} \cdot V^{2}+m_{1} \cdot V+m_{0},
$$

$\mathrm{L}$ - longitudinal dynamic gauge, $\mathrm{m} ; \mathrm{V}$ - speed of the traffic flow, $\mathrm{m} / \mathrm{s} ; \mathrm{m} 2$ - coefficient, $\mathrm{c} 2 / \mathrm{m} ; \mathrm{m} 1$ - coefficient, $\mathrm{c} ; \mathrm{m} 0$ - coefficient, $\mathrm{m}$.

\footnotetext{
* Corresponding author: tgasu.danilov.oleg@mail.ru
} 
The TF density (q) is evaluated by the number of vehicles on the lane with a fixed length and is inversely proportional to the DG

$$
q(V)=1 / L(V)=1 /\left(m_{2} \cdot V^{2}+m_{1} \cdot V+m_{0}\right) .
$$

Intensity $(\mathrm{N})$ is evaluated by the basic equation of the TF connecting the intensity with its density and speed

$$
N(V)=V \cdot q(V)=V /\left(m_{2} \cdot V^{2}+m_{1} \cdot V+m_{0}\right)
$$

DG coefficients $(\mathrm{m} 2, \mathrm{~m} 1, \mathrm{~m} 0)$ were carefully analyzed by the authors.

The classical model of Tanaka (1) does not take into account the factor of speed limitation on different sections of the road network. The solution to the problem of the given model adaptation to any speed rates must meet two requirements:

Firstly, the vehicle speed cannot exceed the given limit Vlim. $=60 \mathrm{~km} / \mathrm{h}$ (chosen is speed limitation for a city);

Secondly, the longitudinal DG appropriate for safe driving must not be violated, i.e. drivers follow the DG with regard to TF density growth.

Here, two issues are of practical interest:

How to describe speed-density ratio analytically ( $\mathrm{Vl}(\mathrm{q}))$ in low values of $\mathrm{q}(0<\mathrm{q}<\mathrm{qa})$;

What are the coordinates of the function transition point $\mathrm{Vl}(\mathrm{q})$ in transition to function VL(q) corresponding to the DG model (A(qa,Va)).

For rational choice of the function $\mathrm{Vl}(\mathrm{q})$ it is necessary to take into account a number of conditions [3]. Firstly, when $\mathrm{q}=0 \mathrm{Vl}(\mathrm{q})=\mathrm{Vl}(0)=\mathrm{Vlim}$. secondly, when $\mathrm{q}>0$ the function must steadily decrease and be differentiable, thirdly, when $\mathrm{q}=\mathrm{qa}$, the condition $\mathrm{Vl}(\mathrm{qa})=\mathrm{VL}$ (qa) must be performed and fourthly, the derivatives of both functions must be equal in the point $\mathrm{A}$. The following function is chosen as $\mathrm{Vl}(\mathrm{q})$ :

$$
V_{l}(q)=V \lim .-K_{l} \cdot q^{2}
$$

Vlim. - maximal speed with regard to limitation, $\mathrm{km} / \mathrm{h} ; \mathrm{Kl}$ - coefficient, $\mathrm{km} 3 / \mathrm{h}$.

The value of $\mathrm{Kl}$ is evaluated from the condition of equality of speeds $\mathrm{Vl}(\mathrm{qa})$ и $\mathrm{VL}(\mathrm{qa})$ in the point A. Taking into account that $\mathrm{Vl}(\mathrm{qa})=\mathrm{VL}(\mathrm{qa})=\mathrm{Va}$, let us find $\mathrm{Kl}$ from (4), expressing the speed in $\mathrm{m} / \mathrm{s}$, and density in Vehicles $/ \mathrm{m}$

$$
K_{l}=\frac{3.6 \cdot\left[V \lim -V_{a}\right]}{1000^{2} \cdot q_{a}^{2}} .
$$

The function VL(q), characterizing TF performance in keeping to the longitudinal DG can be presented in the following way

$$
V_{L}(q)=\frac{-m_{1}+\sqrt{m_{1}^{2}-4 \cdot m_{2} \cdot\left(m_{0}-1 / q\right)}}{2 \cdot m_{2}}
$$

Let us find the derivatives of the functions Vl(qa) and VL(qa) to meet the conditions of their conjugation in the point $A$. In the first case, when applying the equation (4) and transforming $\mathrm{V}$ into $\mathrm{m} / \mathrm{s}$, and $\mathrm{q}$ - into Vehicles/m, we obtain 


$$
\frac{d V_{l}}{d q}=-\frac{2 \cdot K_{l} \cdot 1000^{2} \cdot q_{a}}{3.6}=-\frac{2 \cdot K_{l} \cdot 1000^{2}}{3.6 \cdot L_{a}},
$$

$\mathrm{La}$ - the value of the dynamic gauge in the point $\mathrm{A}$.

Taking into account (1) let us find the derivative of the second function

$$
\frac{d V_{L}}{d q}=-\frac{\left(m_{2} \cdot V_{a}^{2}+m_{1} \cdot V_{a}+m_{0}\right)^{2}}{m_{1}+2 \cdot m_{2} \cdot V_{a}}=-\frac{L_{a}^{2}}{m_{1}+2 \cdot m_{2} \cdot V_{a}} .
$$

Making (7) and (8) equal, we obtain

$$
K_{l}=\frac{3.6 \cdot L_{a}^{3}}{2 \cdot 1000^{2} \cdot\left(m_{1}+2 \cdot m_{2} \cdot V_{a}\right)} .
$$

In here, the condition imposed by the ratio (5), where $\mathrm{qa}=1 / \mathrm{La}$ is needed to be met. Simultaneous solutions (5) and (9) make it possible to note

$$
\begin{aligned}
& \frac{3.6 \cdot\left(V \lim -V_{a}\right) \cdot L_{a}^{2}}{1000^{2}}=\frac{3.6 \cdot L_{a}^{3}}{2 \cdot 1000^{2} \cdot\left(m_{1}+2 \cdot m_{2} \cdot V_{a}\right)}, \\
& 5 \cdot m_{2} \cdot V_{a}^{2}+\left(3 \cdot m_{1}-4 \cdot m_{2} \cdot V_{\text {ozp }}\right) \cdot V_{a}+\left(m_{0}-2 \cdot m_{1} \cdot V_{o z p}\right)=0, \\
& V_{a}=\frac{-\left(3 \cdot m_{1}-4 \cdot m_{2} \cdot V_{\text {ozp }}\right)+\sqrt{\left(3 \cdot m_{1}-4 \cdot m_{2} \cdot V_{\text {ozp }}\right)^{2}-4 \cdot 5 \cdot m_{2} \cdot\left(m_{0}-2 \cdot m_{1} \cdot V_{\text {ozp }}\right)}}{2 \cdot 5 \cdot m_{2}}
\end{aligned}
$$

The equation (10) allows calculating the speed in the conjugation point $\mathrm{A}$, when drivers follow the longitudinal DG.

When studying the association of the TF with its speed, one should consider two intervals. For $0 \leq \mathrm{V} \leq \mathrm{Va}$ the function $\mathrm{N}(\mathrm{V})$ is determined by the ratio (3), and for $\mathrm{Va} \leq \mathrm{V} \leq \mathrm{Vorp}$ it is conditioned by the formula (4), which implies

$$
N(V)=\sqrt{\frac{V \lim \cdot V^{2}-V^{3}}{K_{l}}} .
$$

The DG coefficients should be chosen to develop the basic models of the TF. To do this, the completed algorithms have been used (Danilov et al., 2014). The values of $\mathrm{m} 0=8$ $\mathrm{m}, \mathrm{m} 1=1,6 \mathrm{~s}$ have been taken. The coefficient $\mathrm{m} 2$ is calculated for the rough asphalt concrete pavement and models for different operation conditions of the TF are made: dry pavement, wet clean, wet dirty, compacted snow, soft snow, clear ice (status of the pavement condition is $r=1 . .6$ respectively). Table 1 shows the parameters of the model. 
Table 1. Model parameters for the rough asphalt concrete pavement.

\begin{tabular}{|c|c|c|c|c|}
\hline $\begin{array}{c}\text { Status of the pavement } \\
\text { condition } r\end{array}$ & $m_{2}$ & $V_{a}, \mathrm{~km} / \mathrm{h}$ & $\begin{array}{c}q_{a}, \\
\text { Vehicles/km }\end{array}$ & $K_{l}$ \\
\hline 1 & 0.016159 & 36.02 & 39.02 & 0.015748 \\
\hline 2 & 0.020056 & 36.44 & 38.09 & 0.016235 \\
\hline 3 & 0.026390 & 37.09 & 36.65 & 0.017057 \\
\hline 4 & 0.038427 & 38.17 & 34.15 & 0.018721 \\
\hline 5 & 0.069727 & 40.28 & 28.88 & 0.023651 \\
\hline 6 & 0.312132 & 45.25 & 12.92 & 0.088421 \\
\hline
\end{tabular}

\section{Results}

Fig. 1 illustrates the speed-density ratio of the traffic flow at various states of the road pavement. The conjugation points are highlighted in red. The left parts of the graphs evaluated by (4) are highlighted in blue, and the right ones corresponding to the DG model - in black. It is obvious that for the relatively favorable conditions of road traffic $(r=1.3)$ the curves are hardly ever distinguishable, and conjugation points are concentrated in a small area. In this case it seems reasonable to combine such curves into a single group. In fact, taking into account the applied modeling of the TF, the road conditions are to be differentiated into three types: normal, snowy and icy.

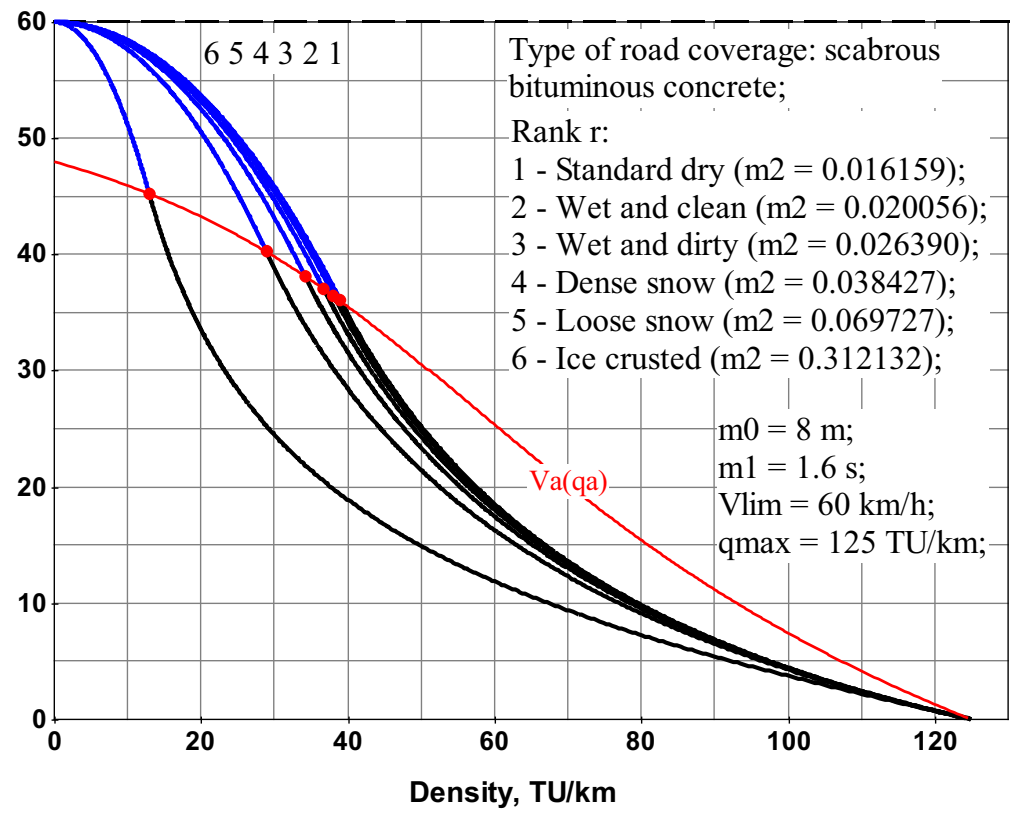

Fig. 1. Speed-density ratio of the traffic flow.

At the same time, the coefficient $\mathrm{m} 2$ determining the shape of the line $\mathrm{V}$ (q) depends on the structure of the TF [4]. Therefore, the calculated values of $\mathrm{m} 2$ (Fig. 1) can be considered conventional complying with the particular case. Thus, needed is the identification of the drift trajectory of the point A, the position of which is caused by the parameter $\mathrm{m} 2$.

Let us express the coefficient $\mathrm{m} 2$ using the simultaneous solution of the equations (5) and (9) 


$$
m_{2}=\frac{2 \cdot m_{1} \cdot V \lim -3 \cdot m_{1} \cdot V_{a}-m_{0}}{5 \cdot V_{a}^{2}-4 \cdot V \lim \cdot V_{a}}
$$

On the other side, as it follows from (3)

$$
m_{2}=\frac{1}{N \cdot V}-\frac{m_{1}}{V}-\frac{m_{0}}{V^{2}}
$$

Making (12) equal to (13) with regard to $\mathrm{V}=\mathrm{Va}$, we obtain the solution

$$
N_{a}=\frac{5 \cdot V_{a}^{2}-4 \cdot V \lim \cdot V_{a}}{2 \cdot m_{1} \cdot V_{a}^{2}-2 \cdot m_{1} \cdot V \lim \cdot V_{a}+4 \cdot m_{0} \cdot V_{a}-4 \cdot m_{0} \cdot V \lim } .
$$

The trajectory of the point $\mathrm{A}(\mathrm{Va}, \mathrm{Na})$ is shown in Fig. 2 (highlighted in red).

As for the position of the point of extremum intensity, here it is necessary to consider two situations. In the interval of $0 \leq \mathrm{V} \leq \mathrm{Va}$ the rate of Nmax advances is determined by finding the derivative of the function (3) making it possible to obtain the formulas

$$
\begin{gathered}
V_{\max N}=\sqrt{m_{0} / m_{2}}, \\
m_{2}=\frac{m_{0}}{V_{\max N}^{2}},
\end{gathered}
$$

$\mathrm{VmaxN}$ - the rate of maximum intensity advances.

Using the simultaneous solutions of (16) and (13) we obtain the following formula taking into account that the actual intensity corresponds to the maximum one:

$$
N_{\max }=\frac{V_{\max N}}{m_{1} \cdot V_{\max N}+2 \cdot m_{0}} .
$$

In the interval of $\mathrm{Va} \leq \mathrm{V} \leq \mathrm{Vlim}$ the speed $\mathrm{VmaxN}$ is in the cross point of the functions $\mathrm{Na}(\mathrm{Va})$ and $\mathrm{Nmax}(\mathrm{VmaxN})$ (marked as $\mathrm{B}(\mathrm{Vb}, \mathrm{Nb})$ ). Point $\mathrm{B}$ is highlighted in dark blue in Fig. 2. The coordinates of $\mathrm{B}$ can be determined analytically making (14) equal to (17) taking into account that $\mathrm{Va}=\mathrm{VmaxN}=\mathrm{Vb}$. Then, after mathematical transformations we obtain

$$
V_{b}=\frac{-\left(6 \cdot m_{0}-2 \cdot m_{1} \cdot V \lim .\right)+\sqrt{\left(6 \cdot m_{0}-2 \cdot m_{1} \cdot V \lim .\right)^{2}-4 \cdot 3 \cdot m_{1} \cdot\left(-4 \cdot m_{0} \cdot V \lim .\right)}}{2 \cdot 3 \cdot m_{1}} .
$$

The analysis (18) suggests that within the interval of $\mathrm{Va} \leq \mathrm{V} \leq \mathrm{Vlim}$. the point of extremum intensity is attained at the fixed rate of $\mathrm{VmaxN}=\mathrm{Vb}$ (Fig. 2). In here, the value of Nmax is evaluated by the formula (11), which implies

$$
N_{\max }=\sqrt{\frac{V \lim \cdot V_{\max N}^{2}-V_{\max N}^{3}}{K_{l}}} .
$$




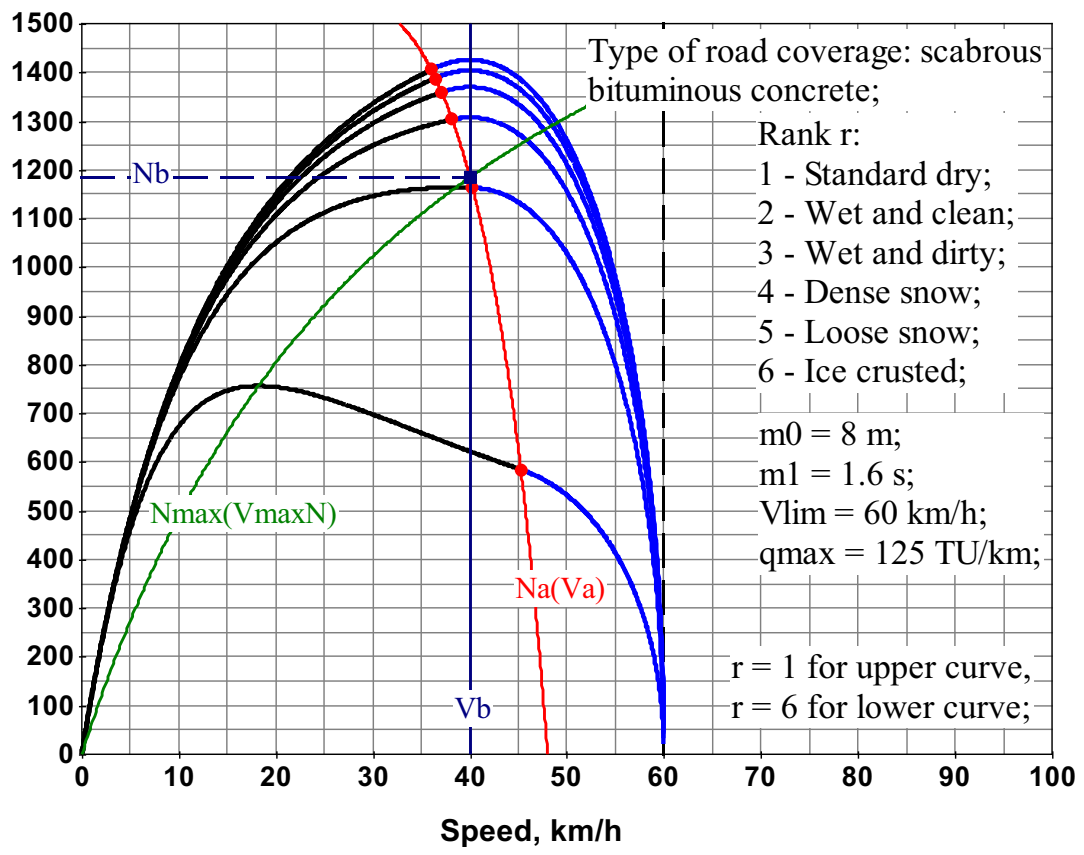

Fig. 2. Intensity-speed ratio of the traffic flow.

In this case, $\mathrm{Vb}=40 \mathrm{~km} / \mathrm{h}$, and $\mathrm{Nb}=1184$ Vehicles $/ \mathrm{h}$. Substituting the data obtained in (13) we find the value of $\mathrm{m} 2$, where the curve $\mathrm{N}(\mathrm{V})$ passes through point $\mathrm{B}$ (the condition $\mathrm{Nmax}=\mathrm{Na}$ is met). We obtain $\mathrm{m} 2=0.064849$. Thus, the developed models with the parameter of $\mathrm{m} 2 \leq 0.064849$ will have the maximum intensity of the TF at the speed of $\mathrm{VmaxN}=\mathrm{Vb}=40 \mathrm{~km} / \mathrm{h}$, and the models with $\mathrm{m} 2 \geq 0.064849$ - at the speed evaluated by the formula (15).

It is obvious that the distance between the vehicles in the density range of $0<\mathrm{q}<\mathrm{qa}$ exceeds the value of DG (Fig. 1). Therefore, further research is needed to introduce the following concept - the average interval of vehicle movement. The average interval of movement (ID) is the distance between the vehicles in traffic environment (TE). For the density interval $\mathrm{qa} \leq \mathrm{q} \leq \mathrm{qmax}$ ID corresponds to the value of the longitudinal $\mathrm{DG} L(\mathrm{~V})$, but the analysis of Fig. 1 suggests that in the range of $0<q<q a$ the condition $\operatorname{ID}(V)>L(V)$ is met. The evolution of the interval of vehicle movement is illustrated in Fig. 3. The black colour shows the function $\mathrm{L}(\mathrm{V})$ to the left of the conjugation point $\mathrm{A}$ (a dotted line marks its theoretical extension). The blue colour shows the function $\operatorname{ID}(\mathrm{V})$ which describes the interval of vehicle movement. Moreover, Fig. 3 illustrates the curve $\mathrm{La}(\mathrm{Va})$ which describes the drift of point A within the changing conditions of the TE (for different values of $\mathrm{m} 2$ ). 


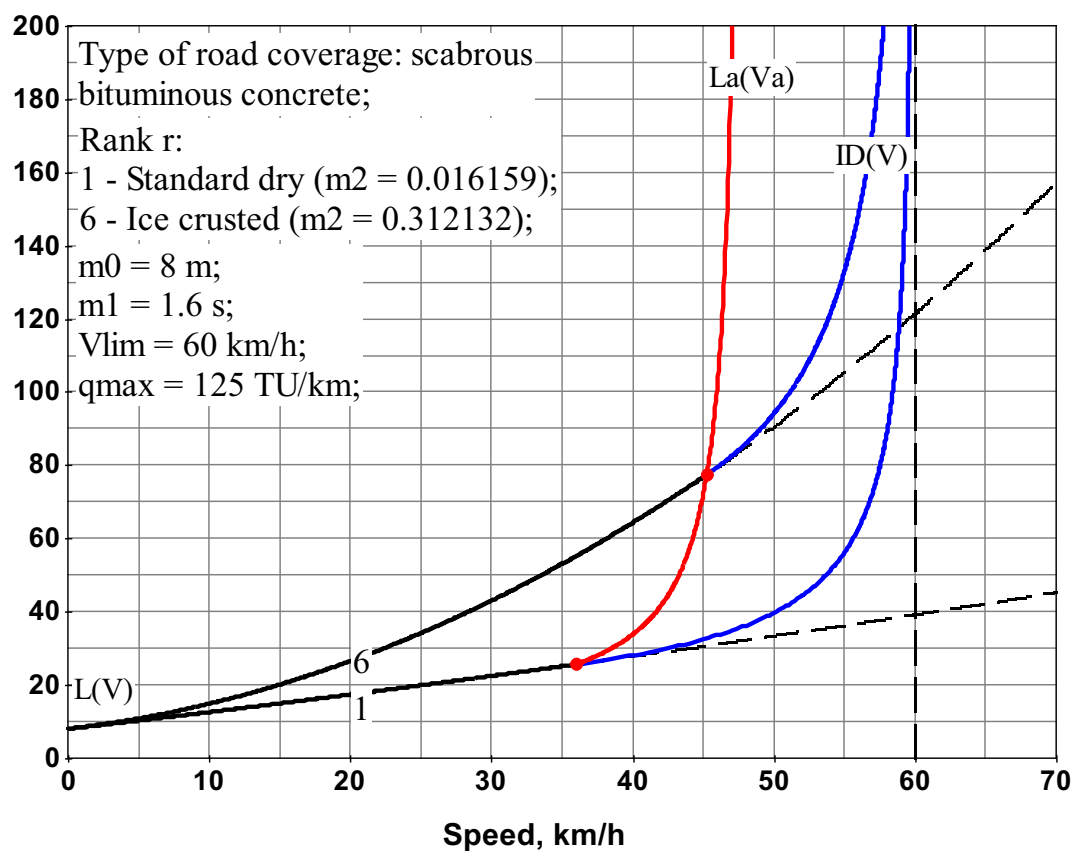

Fig. 3. Dynamics of average interval of movement ID.

It is obvious that the interval of movement in the TE gradually increases if the speed increases within the constraints of $(\mathrm{V} \leq \mathrm{Vlim}$.). This fact radically distinguishes the developed alternate function (4) from the classical model of the DG. It has a logical explanation. Having passed from the associated TF mode to the free one, the driver does not tend to increase the speed of the vehicle to the maximum. In this case, the behaviour of the driver is still conditioned by the distance to the "leader" vehicle. The gist is simple: the greater the distance between the vehicles, the more freely a person feels, and the more subjected he is to speeding. In here, the driver accelerates to the maximum in the absence of vehicles in his visibility distance, or if they are at a great distance.

It should be noted that the developed model makes it possible to track the dynamics and other parameters of the TF, e.g. its capacity. Space-time capacity of the TF (e) is evaluated as the product of TF intensity and density. Proved is the linear interrelation between the levels of the environmental risks arising from the TF on the RNW and the parameter e [5]. The capacity value (taking into account the basic equation of the TF) is evaluated by

$$
e=q N=\frac{N^{2}}{V}=q^{2} V .
$$

For speed intervals $0 \leq \mathrm{V} \leq \mathrm{Va}$ (the DG model) the equation (20) should be transformed with regard to (2); then we obtain the formula

$$
e(V)=\frac{V}{L^{2}(V)}=\frac{V}{\left(m_{2} \cdot V^{2}+m_{1} \cdot V+m_{0}\right)^{2}} .
$$

For the range of $\mathrm{Va} \leq \mathrm{V} \leq \mathrm{Vlim}$. (the alternative model) the capacity will be determined by the ratio between (4) and (11) which implies 


$$
e(V)=\frac{V \cdot(V \lim -V)}{K_{l}}
$$

Fig. 4 illustrates the capacity-speed ratio at two different states of the road pavement (dry road and ice). Black colour illustrates the curve obtained after the DG model; in here, a dotted line marks the theoretical extension to the right of point A. The curve determined by (22) is highlighted in blue (reflecting the dynamics of the TF capacity under speed limitation).

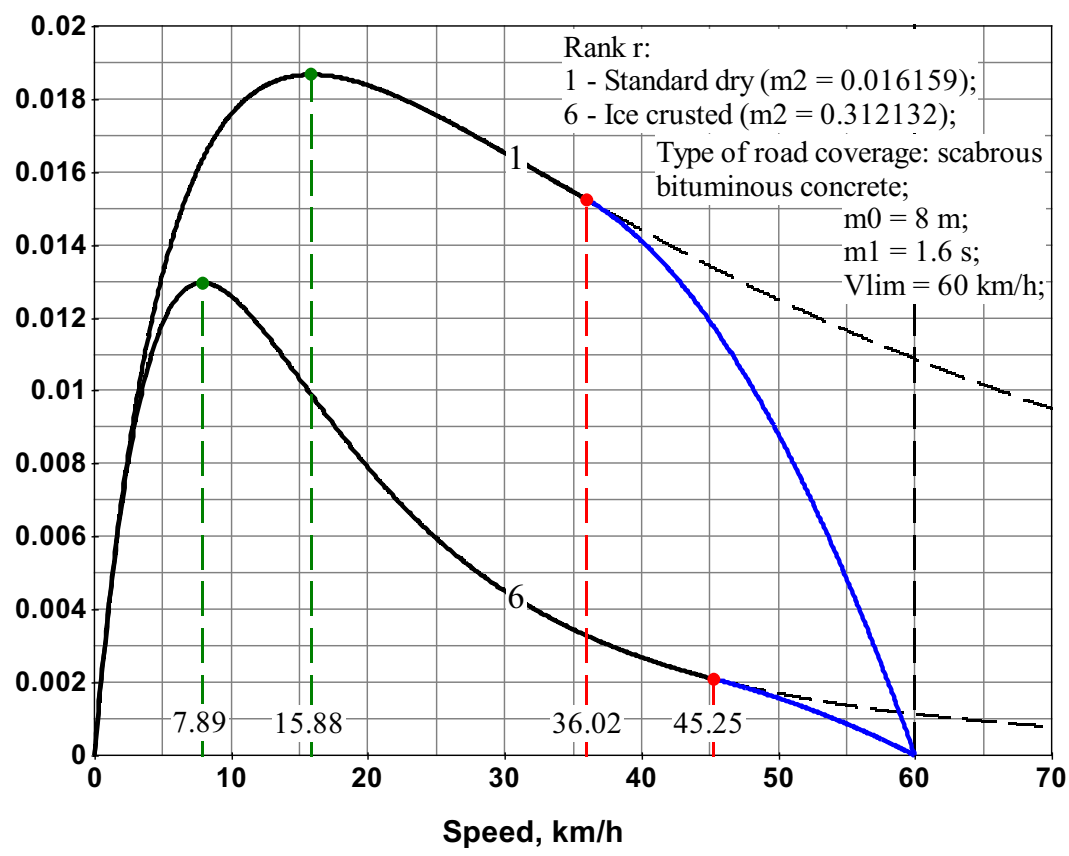

Fig. 4. Capacity-speed ratio of the traffic flow.

The position of the TF capacity extremum is marked in green dot in Fig.4. Obviously, the maximum value of $\mathrm{e}$ is achieved when $\mathrm{de}(\mathrm{V}) / \mathrm{dV}=0$. Then, applying the function (21) let us find its derivative and equate it to zero. After mathematical transformations we obtain the formula for the TF speed achieved in maximum capacity.

$$
V_{\max e}=\frac{-m_{1}+\sqrt{m_{1}^{2}+12 \cdot m_{2} \cdot m_{0}}}{6 \cdot m_{2}}
$$

Vmaxe - speed in attaining TF maximum capacity.

The ultimate value of emax can be evaluated when applying the formula (21) and if the condition $\mathrm{V}=\mathrm{Vmaxe}$ is met.

$$
e_{\max }=\frac{V_{\max e}}{\left(m_{2} \cdot V_{\max e}^{2}+m_{1} \cdot V_{\max e}+m_{0}\right)^{2}} .
$$




\section{Conclusion}

Different types of models that form the basis of modern algorithmization of the subjectmatter have been applied when studying the TF dynamics. Numerous regression curves of the TF speed-density ratio are available to be found in scientific books, but one can fail to find analytical description of the function V(q) in various ranges of the allowable speed. The developed mathematical model of the TF combines both classical and innovative approaches for the comprehensive analysis of the TF dynamic parameters.

The proposed model is a symbiosis of the DG model and the alternative model making it possible to track the dynamics of the TF parameters in terms of speed limitation. The coordinates of the fixed point, where the functions of models conjugate, are determined by the DG coefficients and speed limitation. The point allows determining the boundary of TF phase transition from the "free" state into the "bound" one.

The whole of the mathematical models have been analyzed by soft testing. The results obtained are widely used in experiments aimed at studying transport flows in the city of Tyumen. Based on the approaches given, the authors have developed the mathematical model allowing the effectiveness of the TF performance to be evaluated taking into account the key parameters: TF productivity, road traffic safety and environmental risks.

\section{References}

1. H. Inosje, T. Hamada, Upravlenie dorozhnym dvizheniem (Transport, Moscow, 1983)

2. V. Kolesov, Materialy 5 Vserossijskoj NTK - TjumGNGU, 25-31 (2012)

3. D. Sorokin, V. Kolesov, Materialy Vserossijskoj NPK (Nauchno-Prakticheskoj konferencii). Tjum GNGU, 388-395 (2011)

4. V. Zhdanov, Metod ocenki tehnogennoj opasnosti transportnyh potokov na ulichnodorozhnoj seti goroda. Avtoreferat dissertacii na soiskanie uchenoj stepeni kandidata tehnicheskih nauk. MADI (Moskovskij Avtomobil'no-Dorozhnyj Institut), Moscow, (2008)

5. V. Zhdanov, Sovershenstvovanie metodov rascheta jekologicheskih harakteristik gorodskih transportnyh makroistochnikov (Mashinostroenie, Moscow, 2010)

6. V. Kolesov, D. Sorokin, M. Guljaev, Materialy mezhdunarodnoj NTK - TjumGNGU, 89-95 (2012)

7. V. Kolesov, Materialy mezhdunarodnoj NPK - TjumGNGU, 26-30 (2013)

8. V. Kolesov, Materialy 5 Vserossijskoj NTK - TjumGNG, 25-31 (2012)

9. O. Danilov, V. Kolesov, Materialy mezhdunarodnoj nauchno-prakticheskoj konferencii-Tjum GNGU, 402-405 (2010)

10. A. Moor, O. Danilov, V. Kolesov, Materialy mezhdunarodnoj NTK.- TjumGNGU, 182-193 (2011)

11. A. Moor, O. Danilov, V. Kolesov, TjumGNGU, 167-171 (2012)

12. D. Sorokin, Bezopasnost' na dorogah radi bezopasnosti zhizni: materialy vtorogo oblastnogo foruma, «Vektor Buk», 126-129 (2010)

13. V. Kolesov, Materialy Mezhdunarodnoj NTK. TjumGNGU, 94-103 (2014)

14. V. Krutov, Osnovy nauchny issledovanij: uchebnik dlja tehnicheskih vuzov (Vysshaja shkola, Moscow 1989)

15. S. Ognjenovic, Z. Krakutovski, N. Vatin. Procedia Engineering, 117(1), 564-572 (2015)

16. S. Ognjenovic, R. Donceva, N. Vatin. Procedia Engineering, 117(1), 556-563 (2015)

17. S. Ognjenovic, R. Ristov, N. Vatin. Procedia Engineering, 117(1), 573-578 (2015)

18. S. Ognjenovic, R. Donceva, N. Vatin. Procedia Engineering, 117(1), 549-555 (2015)

19. S. Ognjenovic, Z. Zafirovski, N. Vatin. Procedia Engineering, 117(1), 579-584 (2015) 